\title{
Electrostatic Charges of Abrasive Powders: The Role of Particle Size and Humidity
}

\author{
Alexander Tkach * , Miguel Garcez and Paula M. Vilarinho* \\ Department of Materials and Ceramic Engineering, CICECO-Aveiro Materials Institute, University of Aveiro, \\ 3810-193 Aveiro, Portugal; miguelgarcez@ua.pt \\ * Correspondence: atkach@ua.pt (A.T.); paula.vilarinho@ua.pt (P.M.V.)
}

Citation: Tkach, A.; Garcez, M.; Vilarinho, P.M. Electrostatic Charges of Abrasive Powders: The Role of Particle Size and Humidity. Coatings 2021, 11, 1520. https://doi.org/ $10.3390 /$ coatings 11121520

Academic Editor: Bozena Pietrzyk

Received: 11 November 2021 Accepted: 9 December 2021 Published: 10 December 2021

Publisher's Note: MDPI stays neutral with regard to jurisdictional claims in published maps and institutional affiliations.

Copyright: (c) 2021 by the authors. Licensee MDPI, Basel, Switzerland. This article is an open access article distributed under the terms and conditions of the Creative Commons Attribution (CC BY) license (https:// creativecommons.org/licenses/by/ $4.0 /)$.

\begin{abstract}
Electrostatically coated abrasives have drawn vast attention in many industrial applications. Therefore, influence of humidity on the electrical properties of $\alpha$-SiC and $\alpha-\mathrm{Al}_{2} \mathrm{O}_{3}$ abrasive powders with three $\mu \mathrm{m}$-range particle sizes are here investigated using electrostatic charge and DC resistivity analysis. From the three particle size ranges used, 15-16 $\mu \mathrm{m}, 60-63 \mu \mathrm{m}$ and 153-156 $\mu \mathrm{m}$, the intermediate one $(60-63 \mu \mathrm{m})$ is found to be associated with the highest charge values, measured using a double Faraday cup method, as well as the highest resistivity for both materials. However, comparing $\mathrm{SiC}$ and $\mathrm{Al}_{2} \mathrm{O}_{3}$ powders, the latter ones present about twice larger charges in dry and normal humidity states accompanied by several orders of magnitude larger resistivity. Under humid conditions all the powders reveal diminishing charge and resistivity values.
\end{abstract}

Keywords: grinding coatings; $\mathrm{SiC} ; \mathrm{Al}_{2} \mathrm{O}_{3}$; electrostatic charge; double Faraday cups; zeta potential

\section{Introduction}

Grinding coatings or coated abrasives are widely used in our life from household needs to construction, decoration, furniture and automotive industry. In its turn the fabrication of coatings uses electrostatic method [1], i.e., abrasive powders are attached to a flexible base filled with glue under an electric field. Therefore, knowing the surface electrostatic charges can lead to a better understanding of the particles' interaction with the electric field and surfaces. The measurement and quantification of the surface electrostatic charges of the powder particles is then quite relevant to optimize the fabrication conditions.

There are several possible methods to measure the surface charges, including Kelvin probe microscopy (KPM) and zeta potential (ZP) measurements, but they all have limitations. KPM is one of the most advantageous methods, but it can be applied only to the materials with nm-scale roughness [2]. The granulometry of abrasive powders, following the FEPA (Federation of European Producers of Abrasives) standard, ranges for coated abrasives between P12 and P5000 [3]. The indicated number means the quantity of the abrasive grains per square centimetre of support. The higher number corresponds to the finer sandpaper grains and vice versa. Therefore, KPM is inapplicable for the abrasive powder characterisation with separated particles of micron size range. ZP measurement or zetametry can help to estimate the surface charge and it is a widely used method, but it can only be performed in liquid media and on relatively small particles [4,5]. Finally, the electrostatic charge at the particle surface can be measured using Faraday cup method [6]. A double Faraday cup consists of two stainless steel cylindrical cages, of different sizes, concentrically set and isolated to each other by a Teflon plate. The device is connected to an electrometer with input impedance high enough to measure the charge as small as pC. When the outside cage is grounded to screen out external signals and the powder is dropped in the inner cage, an equal charge is induced on the cage metallic wall, resulting in a potential $V_{c}$ drawn from the capacitor, $C_{f}$, in the feedback loop of the electrometer. The magnitude of the output voltage recorded by the electrometer directly yields the magnitude of the charge, $Q=V_{c} \times C_{f}$, as long as $C_{f}$ is a known parameter of the electrometer [6]. 
The double Faraday cup electrostatic charge measurements of $>99.5 \%$ pure $\mathrm{Al}_{2} \mathrm{O}_{3}$ powders with regular hexagonal particle shape have been reported by Lorite et al. [6] as a function of the particle size, being however concentrated on the particle size below $90 \mu \mathrm{m}$. The charge was found to switch from few $\mathrm{nC} / \mathrm{g}$ negative values to much lower positive values at the particle size of about $1 \mu \mathrm{m}$ [6]. No electrostatic charge characterisation at atmospheric conditions has been reported so far for $\mathrm{SiC}$ powders to the best of our knowledge. Therefore, in this work $\mathrm{SiC}$ and $\mathrm{Al}_{2} \mathrm{O}_{3}$ abrasive powders with over $10 \mu \mathrm{m}$ in average large particles are systematically characterized and compared to establish the relation between the particle size, humidity, resistivity and electrostatic charges.

\section{Materials and Methods}

Commercially available P120, P320 and P1200 black silicon carbide SiC (purity > 99\%) and semi-friable fused aluminium oxide $\mathrm{Al}_{2} \mathrm{O}_{3}$ (purity $>97 \%$ ) abrasive powders from Imerys (Paris, France) were studied in this work. The powder crystal phase was analysed with an X-ray diffractometer PANalytical X'Pert-Pro (Malvern, UK), using $\mathrm{Cu} \mathrm{K} \alpha$ radiation. The $\theta-2 \theta$ scan technique was adopted to collect the X-ray diffraction (XRD) intensity data from $20^{\circ}$ to $80^{\circ}$ with a $0.026^{\circ}$ step. The morphology of the powders was observed by scanning electron microscopy (SEM, Hitachi, S-4100, Tokyo, Japan) under the accelerating potential of $25 \mathrm{kV}$. Compositional analysis of the films was carried out by built-in energy dispersive spectroscopy (EDS) system (QUANTAX 400, Bruker, Billerica, MA, USA). The particle size distributions together with the average particle size were determined by particle size analyser (Coulter LS 230, Indianapolis, IN, USA), using the laser scattering technique in aqueous medium. When possible, the surface charge of the powder particles in the aqueous media was estimated by Zeta-potential measurements carried out in $\mathrm{pH}$ range from 2 to 12 using a Malvern Zeta sizer (Nano ZS, Malvern, Worcestershire, UK).

The surface resistivity of the powder particles as a function of the particle size was evaluated from two probe I-V characterisation using a source meter (Keithley 2410, Cleveland, OH, USA), providing $10 \mathrm{~V}$ potential. The powders with weight of $0.6 \mathrm{~g}$ were located in a cylindrical mould made of Teflon and pressed to $100 \mathrm{MPa}$ with two stainless steel press punches, with diameter of $1 \mathrm{~cm}$, which also served as electrodes. In addition to powders in an untreated state, powders dried at $120{ }^{\circ} \mathrm{C}$ for $24 \mathrm{~h}$ and identically dried powders further exposed to a humid environment for another $24 \mathrm{~h}$ were studied. The environment with relative humidity $(\mathrm{RH})$ of about $91 \%$ was reached using a glove box, where boiling water was placed. The powder surface charge as a function of humidity was measured using the double Faraday cup connected to an electrometer (Keithley 6514, Cleveland, OH, USA) with input impedance of $10^{14} \Omega$, high enough to measure down to $\mathrm{pC}$ charges (see Appendix A, Figure A1). The outside cage of the Faraday cup was grounded to define a reference point, as well as steel scoop used to put $2 \mathrm{~g}$ of the powders into the inner cage without tribo-charge. Before the measurements the powders were dried at $120^{\circ} \mathrm{C}$ for $24 \mathrm{~h}$. The humidity variation was carried out using silica gel and boiling water in a glow-box, where the powders stayed for at least $10 \mathrm{~min}$ before the measurement. All the electrical measurements were repeated at least 3 times for each powder to define the measurement uncertainty.

\section{Results and Discussion}

XRD patterns of $\mathrm{SiC}$ and $\mathrm{Al}_{2} \mathrm{O}_{3}$ powders are shown in Figure 1. While $\mathrm{Al}_{2} \mathrm{O}_{3}$ powders reveal mainly $\alpha$-phase (corundum) [7] with structure shown in inset of Figure 1b, SiC present $4 \mathrm{H}$ - and $6 \mathrm{H}$-modifications of $\alpha$-phase [8,9], with the phase ratio of about $1: 2$ and structures indicated in inset of Figure 1a. The phase ratio was determined by HighScore Plus software, associated with the XRD equipment, using the reference intensity ratio method. 


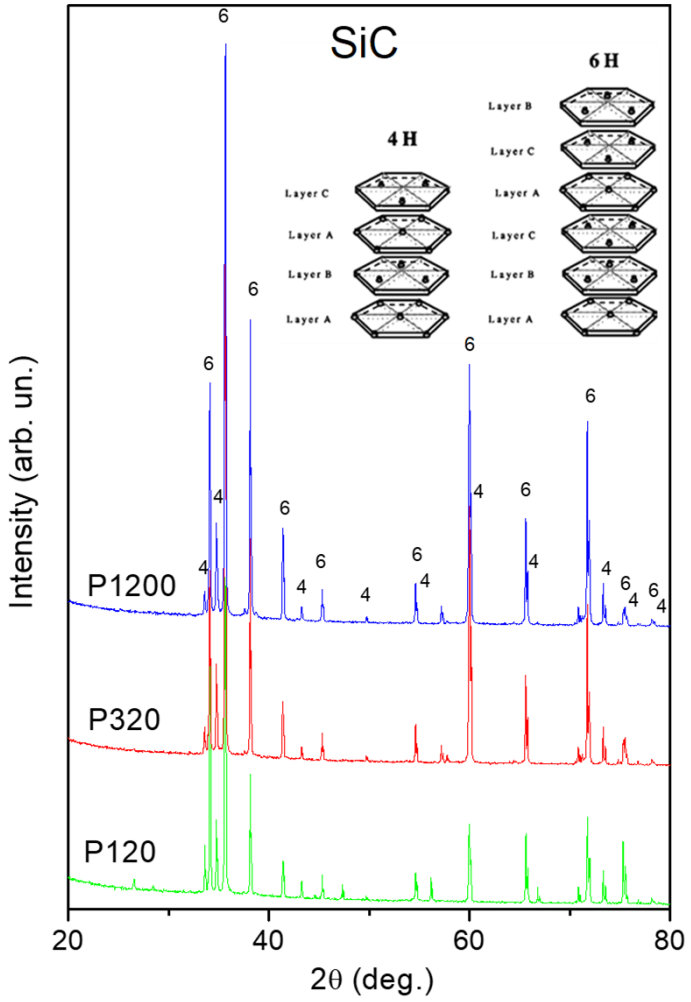

(a)

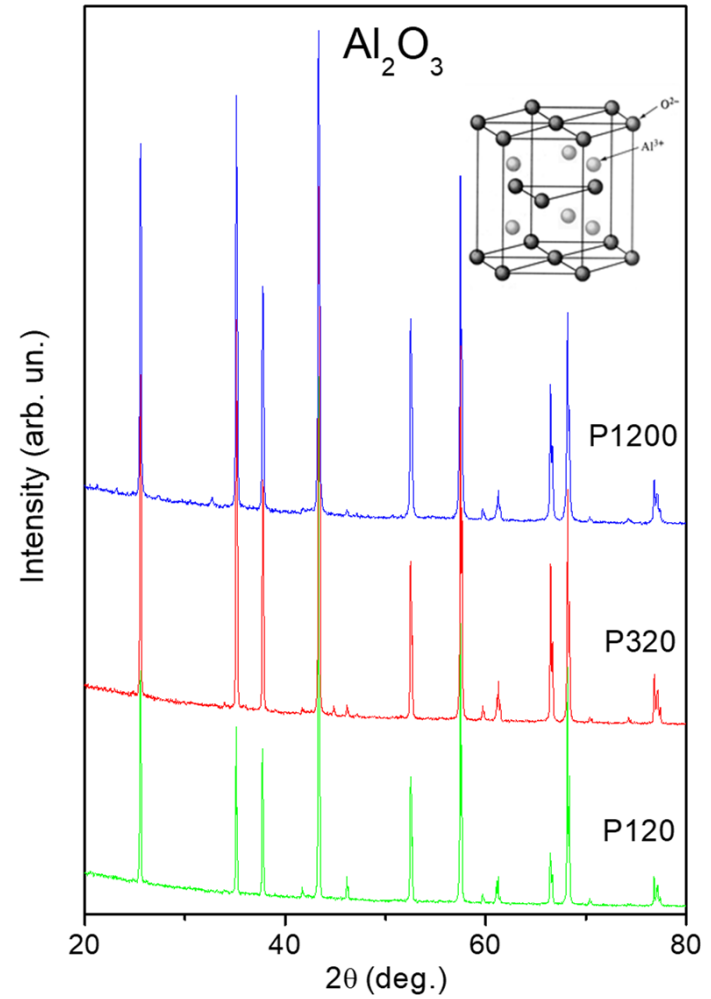

(b)

Figure 1. XRD patterns of $\mathrm{P} 1200$ (top), $\mathrm{P} 320$ (middle) and $\mathrm{P} 120$ (bottom) $\mathrm{SiC}$ (a) and $\mathrm{Al}_{2} \mathrm{O}_{3}$ (b) powders. Insets illustrate the crystal structure of $\mathrm{SiC}\left(4 \mathrm{H}\right.$ and $6 \mathrm{H}$ polymorphs) and $\mathrm{Al}_{2} \mathrm{O}_{3}$ (corundum). Peaks marked by numbers 4 and 6 indicate XRD lines corresponding to $4 \mathrm{H}$ and $6 \mathrm{H}$ phases of $\mathrm{SiC}$, respectively.

SEM micrographs presented in Figure 2 evidence the sharp angle morphology of the powder particles independently on the powder material and particle size, as should be expected for abrasive powders rather different from alumina powders with smooth hexagonal particle shape reported by Lorite et al. [6]. Figure 3 provides the particle size distribution and average size values for $\mathrm{SiC}$ and $\mathrm{Al}_{2} \mathrm{O}_{3}$ P120, P320 and P1200 powders. There are evident main peaks and average particle values of 15-16 $\mu \mathrm{m}$ for P1200, 60-63 $\mu \mathrm{m}$ for P320 and 153-156 $\mu \mathrm{m}$ for P120 powders.

$\mathrm{SiC}$

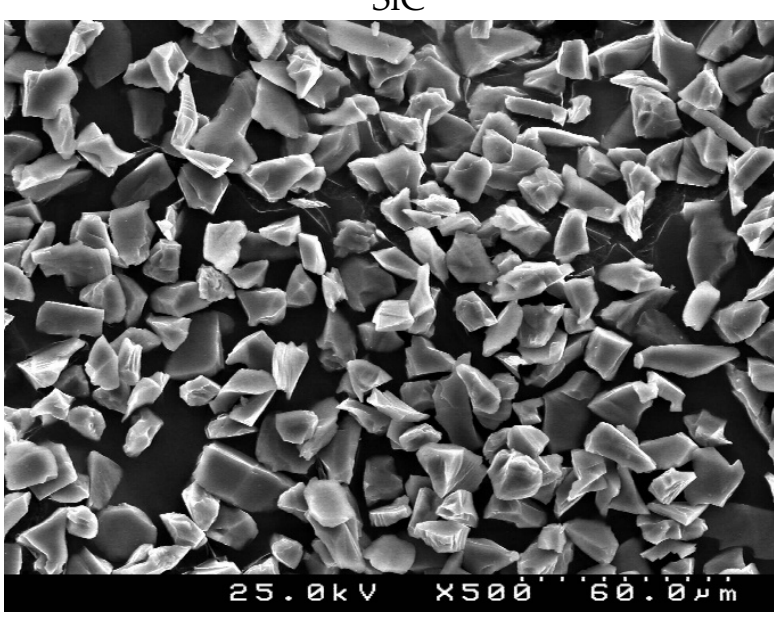

(a)
$\mathrm{Al}_{2} \mathrm{O}_{3}$

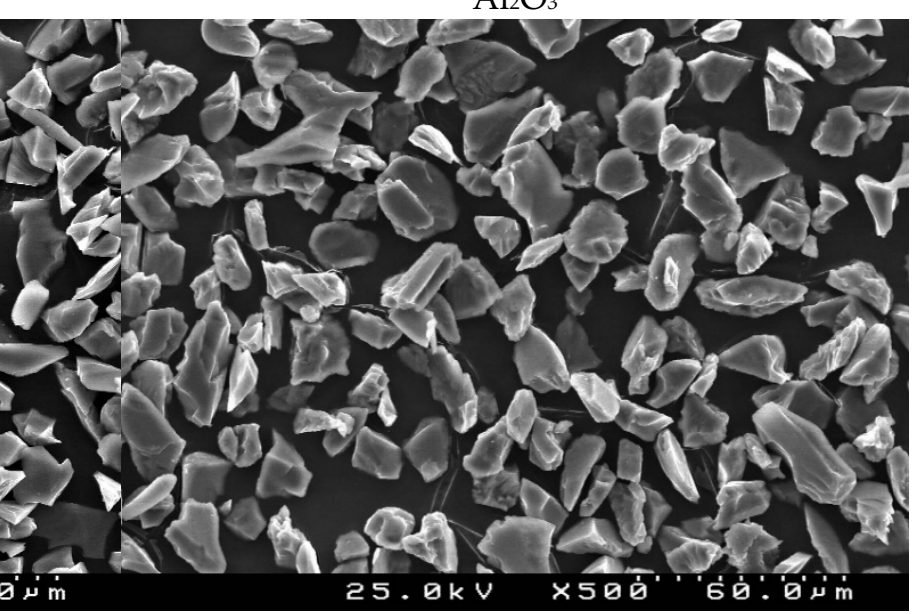

(b)

Figure 2. Cont. 


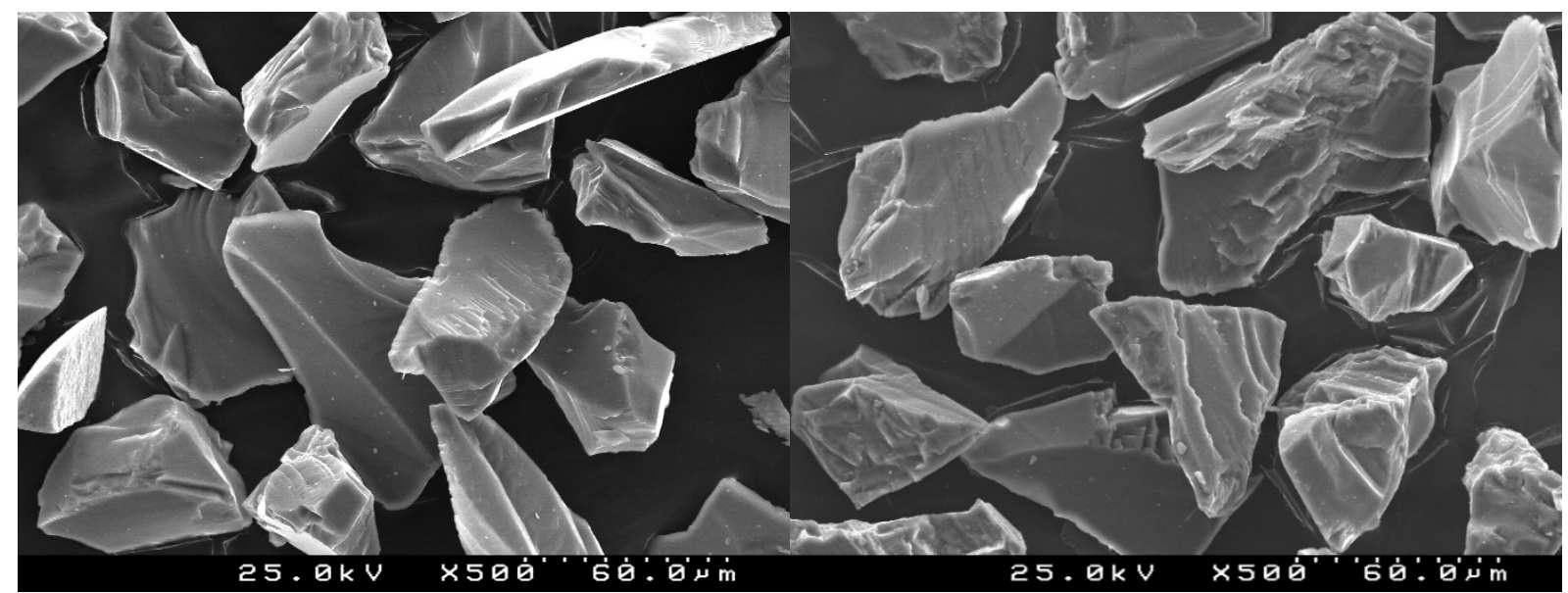

(c)

(d)

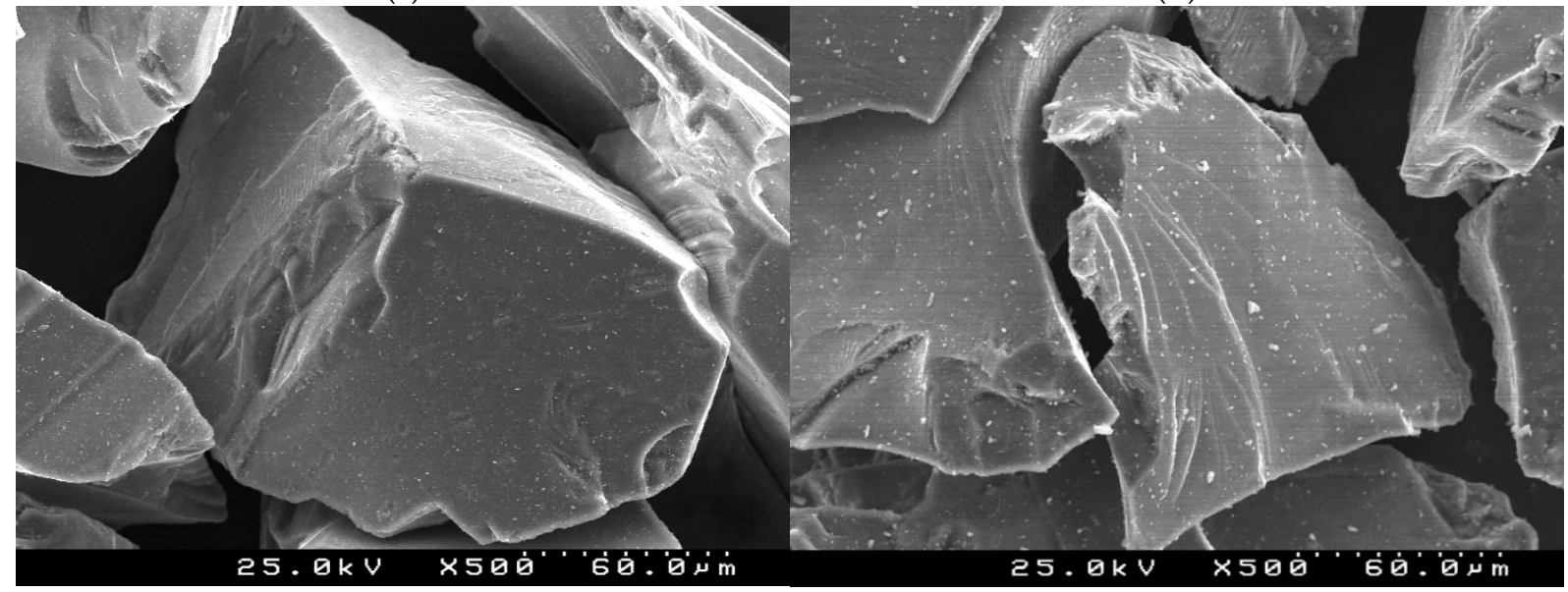

(e)

(f)

Figure 2. SEM micrographs of $\mathrm{P} 1200(\mathbf{a}, \mathbf{b}), \mathrm{P} 320(\mathbf{c}, \mathbf{d})$ and $\mathrm{P} 120(\mathbf{e}, \mathbf{f}) \mathrm{SiC}(\mathbf{a}, \mathbf{c}, \mathbf{e})$ and $\mathrm{Al}_{2} \mathrm{O}_{3}(\mathbf{b}, \mathbf{d}, \mathbf{f})$ powders.

As mentioned in the introduction, zeta potential measurements can be used for estimation of the particle surface charges, but with limitations. As a result, we could also perform these measurements but only for $\mathrm{P} 320$ and $\mathrm{P} 1200 \mathrm{SiC}$ and $\mathrm{Al}_{2} \mathrm{O}_{3}$ powders, whereas average particle size of $\mathrm{P} 120$ powders appeared to be too large for reliable ZP determination. In general, $\mathrm{ZP}$ values were found to be negative for both P320 and P1200 $\mathrm{SiC}$ and $\mathrm{Al}_{2} \mathrm{O}_{3}$ particles, as seen in Figure 4 . The absolute value increases with increasing $\mathrm{pH}$ value, particularly in the low-pH acidic range. A tendency towards a magnification of the negative zeta potentials with increasing $\mathrm{pH}$ is observed due to deprotonation of the surface hydroxyls [5]. In the high- $\mathrm{pH}$ basic range, $\mathrm{ZP}$ absolute values are slightly higher for $\mathrm{Al}_{2} \mathrm{O}_{3}$ comparing with $\mathrm{SiC}$ particles, independently on the particle size. That points to the higher surface charge for $\mathrm{Al}_{2} \mathrm{O}_{3}$ particles in regard to $\mathrm{SiC}$ ones, at least in the basic liquid media. 


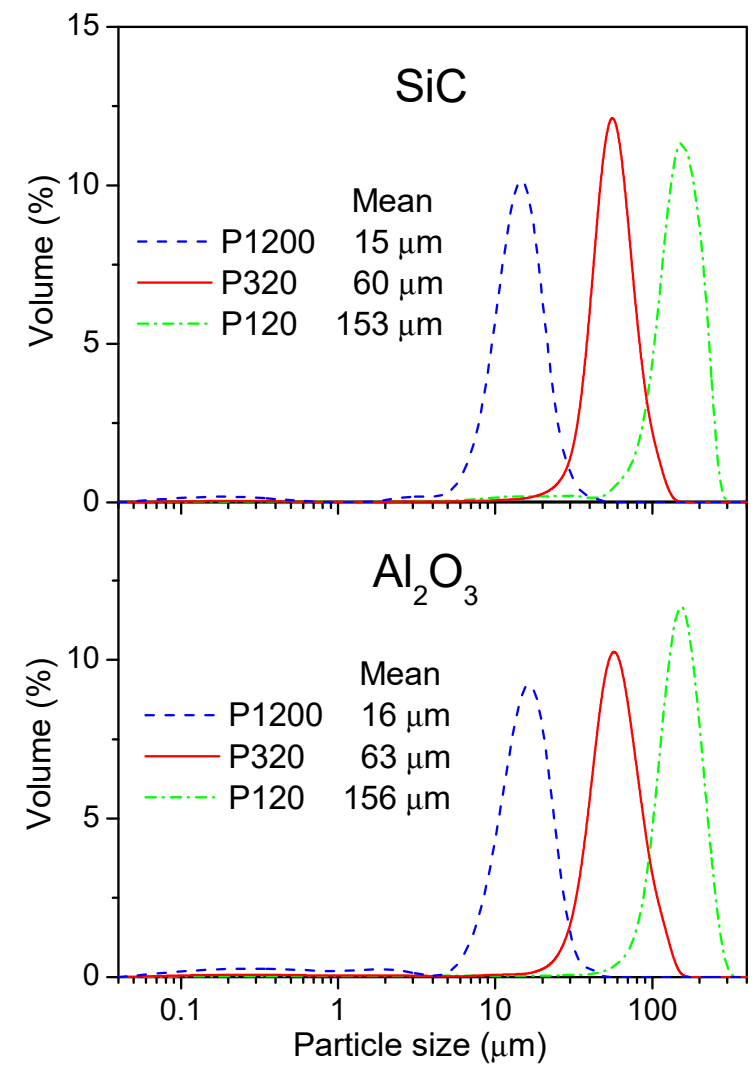

Figure 3. Particle size distribution of P1200 (dash line), P320 (solid line) and P120 (dash-dot line) SiC (top) and $\mathrm{Al}_{2} \mathrm{O}_{3}$ (bottom) powders of together with their mean size values.

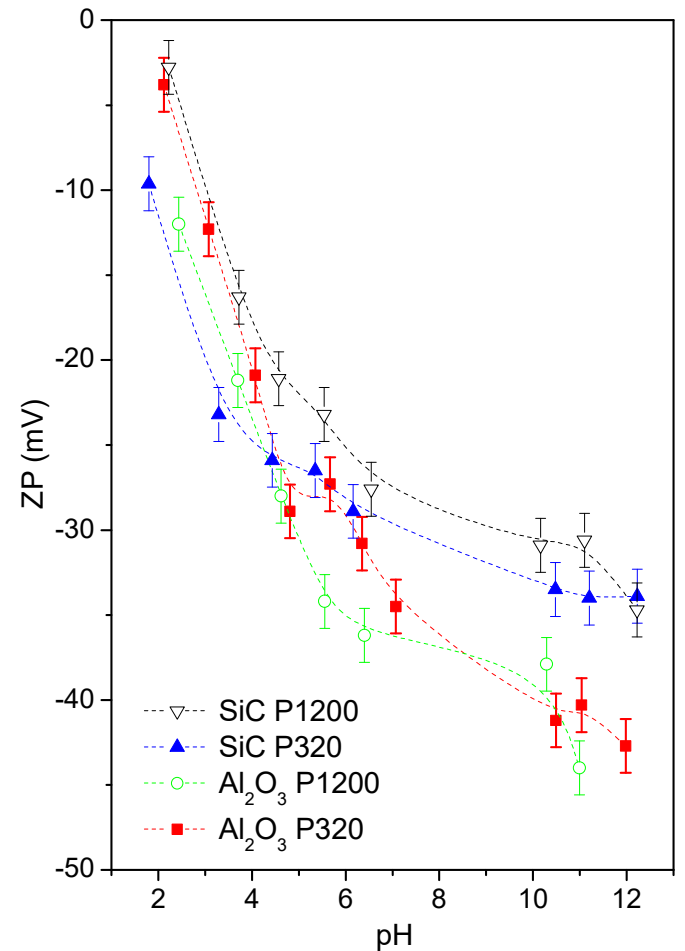

Figure 4. Zeta potential ZP of SiC P1200 (open triangles), SiC P320 (solid triangles), $\mathrm{Al}_{2} \mathrm{O}_{3} \mathrm{P} 1200$ (open circles) and $\mathrm{Al}_{2} \mathrm{O}_{3} \mathrm{P} 320$ (solid squares) powders as a function of $\mathrm{pH}$. Lines are guides to the eye. P120 could not be reliably measured because of too large average particle size. The continuously negative $\mathrm{ZP}$ values observed in these powders is related to silica contribution. 
According to the literature, however, $\mathrm{ZP}$ of both $\mathrm{SiC}$ and particularly $\mathrm{Al}_{2} \mathrm{O}_{3}$ is known to switch from positive to negative when $\mathrm{pH}$ increases with isoelectric point above 8 for $\mathrm{Al}_{2} \mathrm{O}_{3}$ and below 5.5 for $\mathrm{SiC}[4,10]$. On the other hand, composites of $\mathrm{Al}_{2} \mathrm{O}_{3}$ with $\mathrm{SiO}_{2}$ were reported to have no isoelectric point, revealing negative $\mathrm{ZP}$ for $\mathrm{pH}$ values from 2 to $11[5,11]$. Therefore, we have performed EDS analysis of the commercial powders under study and found out peaks corresponding to $\mathrm{Si}$ in spectra of semi-friable fused aluminium oxide and peaks of $\mathrm{O}$ in spectra of black silicon carbide, both indicating the formation of silicon oxide (see Appendix A, Figure A2). Thus, continuously negative ZP values observed in this work should be related to silica contribution.

The powder resistivity of $\mathrm{SiC}$ and $\mathrm{Al}_{2} \mathrm{O}_{3}$ as a function of average particle size is presented in Figure 5 at different humidity conditions. Untreated powders have rather different electrical resistivity of about $10^{6} \Omega \mathrm{cm}$ for $\mathrm{SiC}$ and $10^{8}-10^{10} \Omega \mathrm{cm}$ for $\mathrm{Al}_{2} \mathrm{O}_{3}$. For both $\mathrm{SiC}$ and $\mathrm{Al}_{2} \mathrm{O}_{3}$ powders the resistivity is larger for $\mathrm{P} 320$ powders with intermediate average particle size of 60-63 $\mu \mathrm{m}$. However, rather similar values in order of $10^{6} \Omega \mathrm{cm}$ are recorded for $\mathrm{SiC}$ and $\mathrm{Al}_{2} \mathrm{O}_{3}$ powders when they are measured after wetting in atmosphere of $91 \%$ RH. On the other hand, the resistivities measured for the powders dried in atmosphere of $17 \% \mathrm{RH}$ behave very differently for $\mathrm{SiC}$ and $\mathrm{Al}_{2} \mathrm{O}_{3}$. For $\mathrm{SiC}$, no significant variation is observed, implying that surface modification effect is masked by intrinsically somewhat low resistivity of $\mathrm{M} \Omega \mathrm{cm}$ order. Similar order of resistivity was reported for $\mathrm{SiC}$ powder with average particle size of $54 \mu \mathrm{m}$ [12]. For $\mathrm{Al}_{2} \mathrm{O}_{3}$, however, there is up to 5 orders of magnitude variation between the resistivities of humid and dry powders, while untreated powder reveals intermediate values. Similar variation of the powder resistivity with humidity has been reported for $\mathrm{Al}_{2} \mathrm{O}_{3}$ powders with $320-\mu \mathrm{m}$ mean diameter [13]. Such high variation indicates that the resistivity of intrinsically insulator $\mathrm{Al}_{2} \mathrm{O}_{3}$ can be strongly suppressed by the humidity effect on enhanced surface area, characteristic for powders.
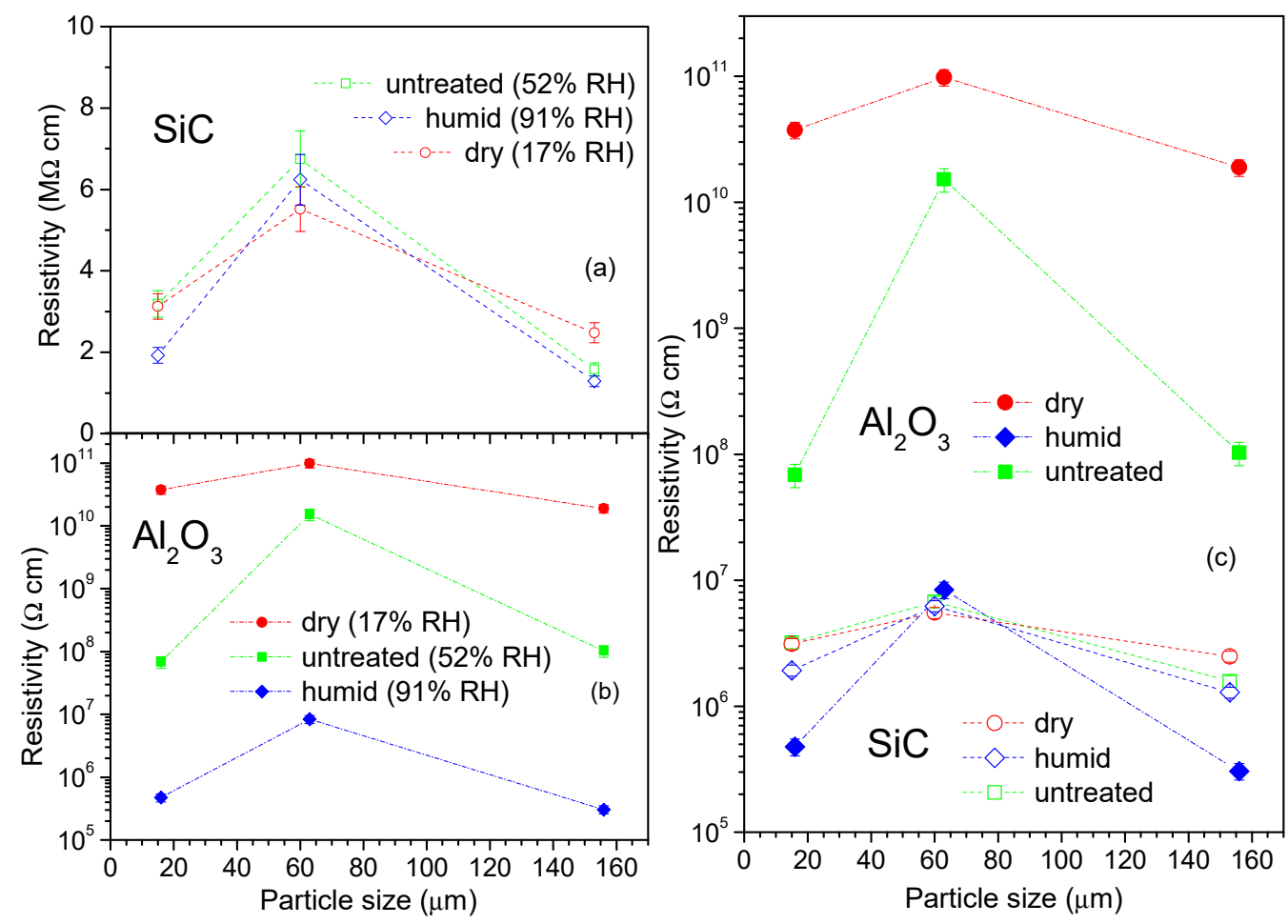

Figure 5. Resistivity of $\mathrm{SiC}(\mathbf{a}), \mathrm{Al}_{2} \mathrm{O}_{3}$ (b) and both $\mathrm{SiC}$ (open symbols) and $\mathrm{Al}_{2} \mathrm{O}_{3}$ (solid symbols) powders (c) as a function of average particle size at $17 \% \mathrm{RH}$ (circles), $52 \% \mathrm{RH}$ (squares) and $91 \% \mathrm{RH}$ (diamonds). Lines are guides to the eye. 
The electrostatic charge values are shown in Figure 6 as a function of humidity for $\mathrm{SiC}$ and $\mathrm{Al}_{2} \mathrm{O}_{3} \mathrm{P} 120, \mathrm{P} 320$ and $\mathrm{P} 1200$ powders. Identically to the resistivity, the highest charge with negative sign (the same as the sign of $\mathrm{ZP}$ ) is measured for $\mathrm{Al}_{2} \mathrm{O}_{3} \mathrm{P} 320$ powders, reaching up to $1.6 \mathrm{nC} / \mathrm{g}$ in absolute value. The charge is about twice higher than that for SiC P320 powders and much higher than that of sub-nC/g range for all other powders at humidity values below 50\%. However, when humidity increases toward $91 \% \mathrm{RH}$ the electrostatic charge diminishes for all the powders in correlation with the surface resistivity decrease observed in Figure 5b.

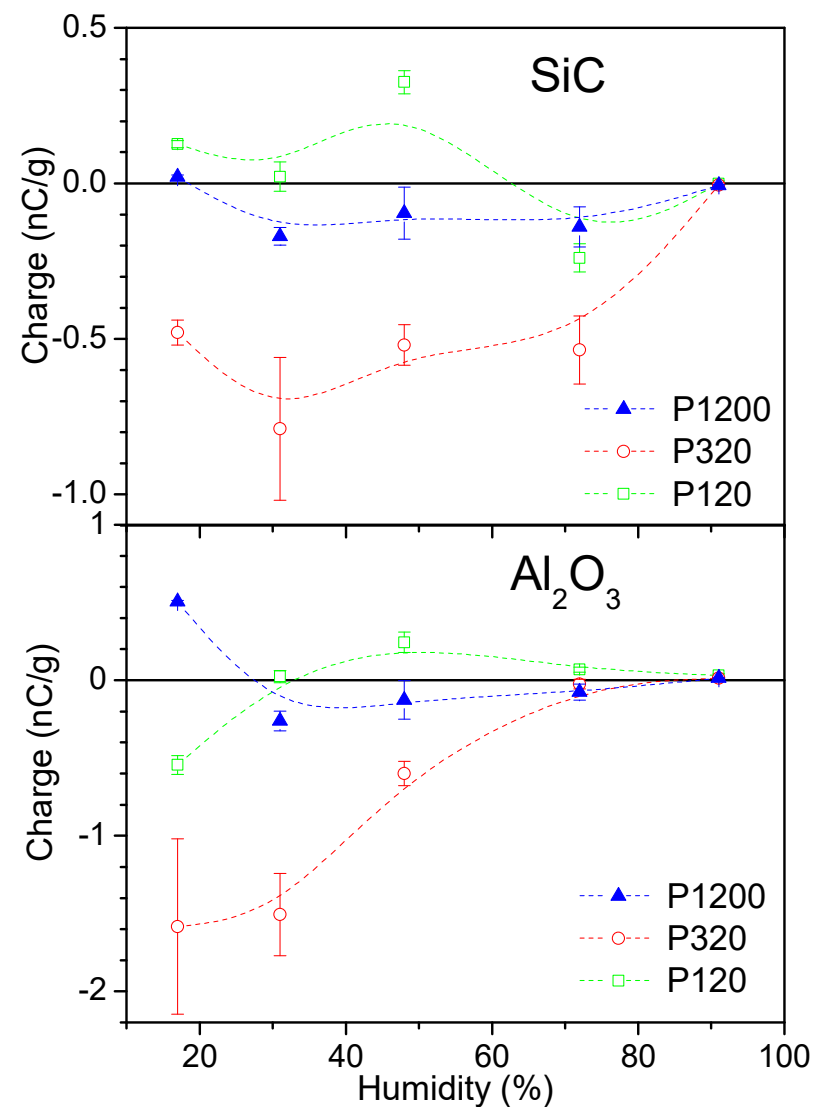

Figure 6. Electrostatic charge of P1200 (solid triangles), P320 (open circles) and P120 (open squares) $\mathrm{SiC}$ (top) and $\mathrm{Al}_{2} \mathrm{O}_{3}$ (bottom) powders. Lines are guides to the eye.

Here we advocate that the non-monotonous behaviour between the smallest particles of both powders and the ones of the biggest particle size might be related with some interplay between the raw material and silica additive properties from one side and the surface area variation from another side. Lower surface areas associated with the largest particle size will decrease the reactivity of these powders and, hence, the reactivity towards humidity, surface charges and resistivity. Regarding the considerable charge values observed on nominally semiconducting $\mathrm{SiC}$ powders, revealing up to 5 orders of magnitude lower resistivity than that of $\mathrm{Al}_{2} \mathrm{O}_{3}$, it can be attributed as well to the formation of silicon oxide surface layer [14].

\section{Conclusions}

In this work a comparative study of $\alpha-\mathrm{SiC}$ and $\alpha-\mathrm{Al}_{2} \mathrm{O}_{3}$ abrasive powders was performed and the relation between the particle size, humidity, resistivity and electrostatic charge was established. In terms of particle size, 15-16 $\mu \mathrm{m}, 60-63 \mu \mathrm{m}$ and 153-156 $\mu \mathrm{m}$, the intermediate one is found to be associated with the highest charge values as well as the highest resistivity for both materials. However, comparing $\mathrm{SiC}$ and $\mathrm{Al}_{2} \mathrm{O}_{3}$ powders, the latter ones present about twice larger charges measured using a double Faraday cup method 
in dry and normal humidity atmosphere conditions accompanied by several orders of magnitude larger resistivity. At humid conditions all the powders reveal diminishing charge and resistivity values. Significant charge values observed on nominally semiconducting $\mathrm{SiC}$ powders are attributed to the formation of silica surface layer.

Author Contributions: Conceptualization, P.M.V.; methodology, A.T. and M.G.; validation, M.G.; formal analysis, A.T. and P.M.V.; investigation, M.G. and A.T.; resources, P.M.V.; data curation, M.G.; writing —original draft preparation, A.T.; writing — review and editing, P.M.V. and A.T.; visualization, A.T.; supervision, P.M.V. and A.T.; project administration, P.M.V.; funding acquisition, P.M.V. All authors have read and agreed to the published version of the manuscript.

Funding: This work was developed within the scope of the project CICECO-Aveiro Institute of Materials, UIDB/50011/2020 and UIDP/50011/2020, financed by national funds through the Portuguese Foundation for Science and Technology/MCTES.

Institutional Review Board Statement: Not applicable.

Informed Consent Statement: Not applicable.

Data Availability Statement: The data presented in this study are available on request from the corresponding author.

Conflicts of Interest: The authors declare no conflict of interest.

\section{Appendix A}

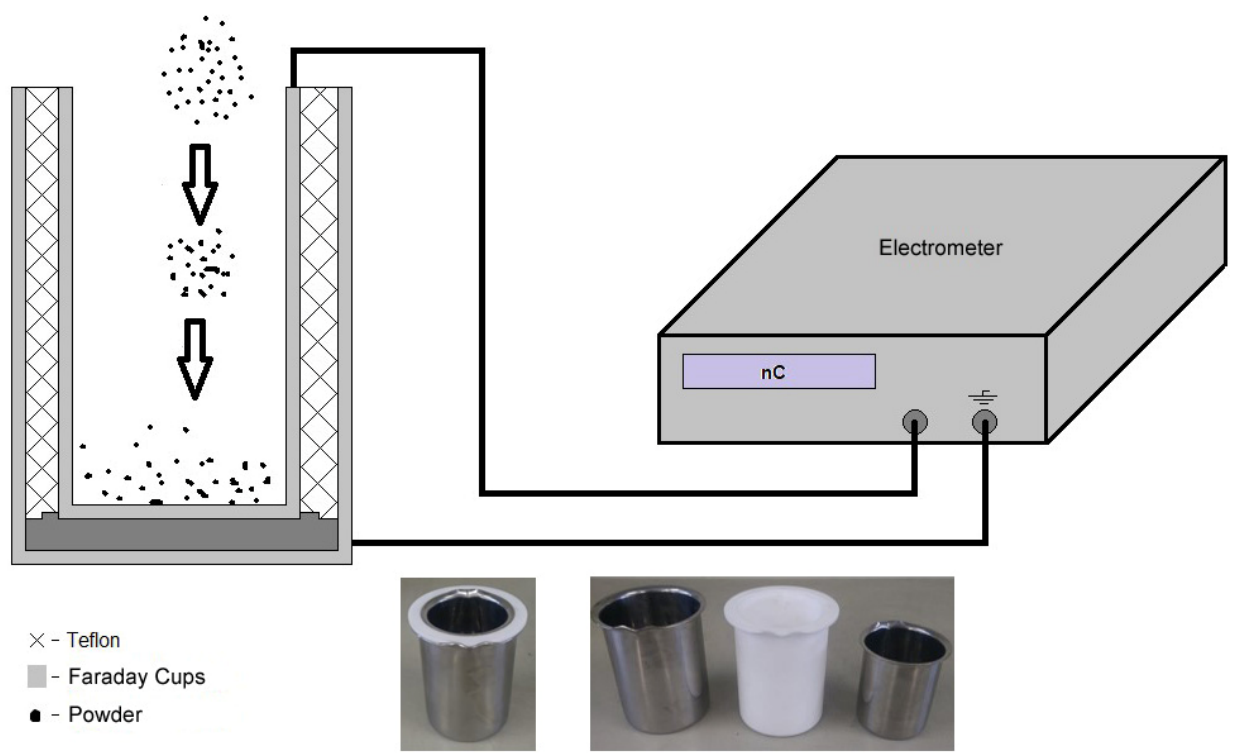

Figure A1. Scheme of double Faraday cup method for powder surface charge measurement, including presentation of the cups and their components. 


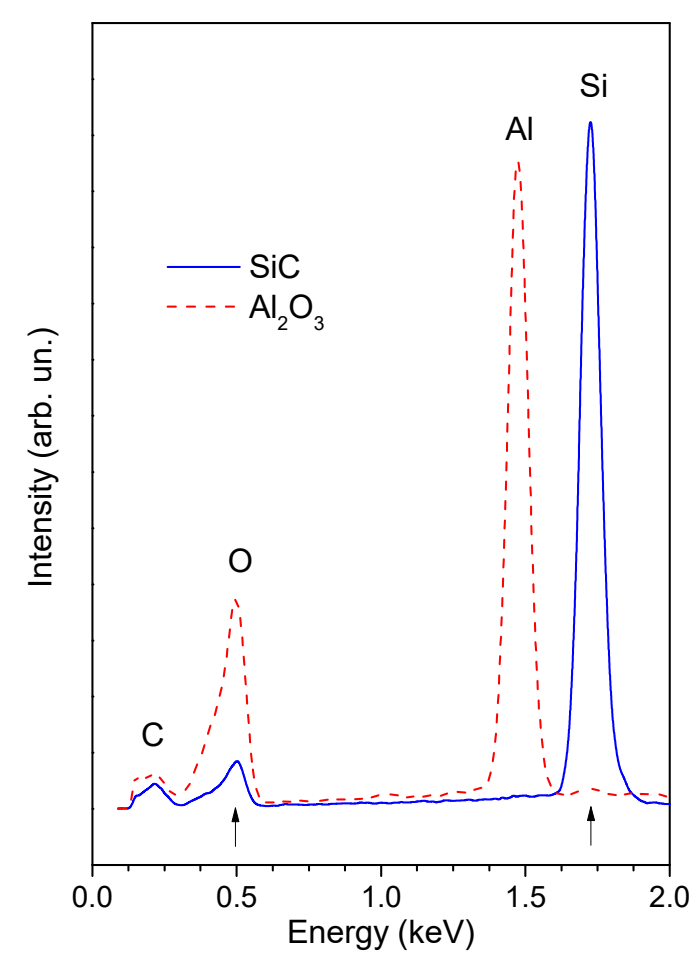

Figure A2. Energy dispersive spectra of commercial black silicon carbide SiC (solid line) and semifriable fused aluminium oxide $\mathrm{Al}_{2} \mathrm{O}_{3}$ (dash line), indicating presence of silicon oxide in both powders.

\section{References}

1. Moren, L.S.; Koethe, B.G.; Boden, J.T. Electrostatic Abrasive Particle Coating Apparatus and Method. Patent WO2012/112322 A2, 23 August 2012. Available online: http:/ / www.google.com/patents/WO2012112322A2?cl=en (accessed on 9 December 2021).

2. Gouveia, R.F.; Galembeck, F. Electrostatic charging of hydrophilic particles due to water adsorption. J. Am. Chem. Soc. 2009, 131, 11381-11386. [CrossRef] [PubMed]

3. Federation of European Producers of Abrasives-FEPA Grain Standards. Available online: https://fepa-abrasives.org/categorieproduit/grains / (accessed on 25 October 2021).

4. Hashiba, M.; Okamoto, H.; Nurishi, Y.; Hiramatsu, K. The zeta-potential measurement for concentrated aqueous suspension by improved electrophoretic mass transport apparatus-Application to $\mathrm{Al}_{2} \mathrm{O}_{3}, \mathrm{ZrO}_{3}$ and $\mathrm{SiC}$ suspensions. J. Mater. Sci. 1988, 23, 2893-2896. [CrossRef]

5. Gun'ko, V.M.; Zarko, V.I.; Leboda, R.; Chibowski, E. Aqueous suspension of fumed oxides: Particle size distribution and zeta potential. Adv. Colloid Interface Sci. 2001, 91, 1-112. [CrossRef]

6. Lorite, I.; Martin-Gonzalez, M.S.; Romero, J.J.; Garcia, M.A.; Fierro, J.L.G.; Fernandez, J.F. Electrostatic charge dependence on surface hydroxylation for different $\mathrm{Al}_{2} \mathrm{O}_{3}$ powders. Ceram. Int. 2012, 38, 1427-1434. [CrossRef]

7. Newnham, R.E.; de Haan, Y.M. Refinement of the $\alpha \mathrm{Al}_{2} \mathrm{O}_{3}, \mathrm{Ti}_{2} \mathrm{O}_{3}, \mathrm{~V}_{2} \mathrm{O}_{3}$ and $\mathrm{Cr}_{2} \mathrm{O}_{3}$ structures. Z. Kristallogr. Cryst. Mater 1962, 117, 235-237. [CrossRef]

8. Frevel, L.K.; Petersen, D.R.; Saha, C.K. Polytype distribution in silicon carbide. J. Mater. Sci. 1992, 27, 1913-1925. [CrossRef]

9. Ortiz, A.L.; Cumbrera, F.L.; Sanchez-Bajo, F.; Guiberteau, F.; Xu, H.; Padture, N.P. Quantitative phase-composition analysis of liquid-phase-sintered silicon carbide using the rietveld method. J. Am. Ceram. Soc. 2000, 83, 2282-2286. [CrossRef]

10. Jaafar, M.; Fantozzi, G.; Reveron, H. Preparation and characterization of pressureless sintered alumina $/ 5 \mathrm{vol} . \% \mathrm{SiC} \mathrm{micro}-$ nanocomposites. Ceramics 2018, 1, 13-25. [CrossRef]

11. Zhu, X.; Jiang, D.; Tan, S. Preparation of silicon carbide reticulated porous ceramics. Mater. Sci. Eng. A 2002, 323, 232-238. [CrossRef]

12. Bouanga, C.V.; Savoie, S.; Fréchette, M.F.; Couderc, H.; David, E. Electrical resistivity characterization of silicon carbide by various methods. In Proceedings of the 2012 IEEE International Symposium on Electrical Insulation, San Juan, PR, USA, 10-13 June 2012; pp. 43-47. [CrossRef]

13. Favre, F.; Villieras, F.; Duval, Y.; McRae, E.; Rapin, C. Influence of relative humidity on electrical properties of $\alpha$ - $\mathrm{Al}_{2} \mathrm{O}_{3}$ powders: Resistivity and electrochemical impedance spectroscopy. J. Colloid Interface Sci. 2005, 286, 615-620. [CrossRef] [PubMed]

14. Biggerstaff, T.L.; Reynolds, C.L., Jr.; Zheleva, T.; Lelis, A.; Habersat, D.; Haney, S.; Ryu, S.-H.; Agarwal, A.; Duscher, G. Relationship between $4 \mathrm{H}-\mathrm{SiC} / \mathrm{SiO}_{2}$ transition layer thickness and mobility. Appl. Phys. Lett. 2009, 95, 032108. [CrossRef] 